\title{
Antifungal activity of dimethyl sulfoxide against Botrytis cinerea and phytotoxicity on tomato and lettuce plants
}

\section{Petruccelli, E. Brasili, L. Varone, A. Valletta \& G. Pasqua}

To cite this article: V. Petruccelli, E. Brasili, L. Varone, A. Valletta \& G. Pasqua (2020) Antifungal activity of dimethyl sulfoxide against Botrytis cinerea and phytotoxicity on tomato and lettuce plants, Plant Biosystems - An International Journal Dealing with all Aspects of Plant Biology, 154:4, 455-462, DOI: $10.1080 / 11263504.2020 .1779846$

To link to this article: https://doi.org/10.1080/11263504.2020.1779846

Published online: 26 Jun 2020.

Submit your article to this journal $\sqsubset$

Џ Article views: 71

a

View related articles $\llbracket$

View Crossmark data $₫$ 


\title{
Antifungal activity of dimethyl sulfoxide against Botrytis cinerea and phytotoxicity on tomato and lettuce plants
}

\author{
V. Petruccelli*, E. Brasili*, L. Varone, A. Valletta and G. Pasqua \\ Department of Environmental Biology, Sapienza University of Rome, Rome, Italy
}

\begin{abstract}
For the first time the antifungal activity of dimethyl sulfoxide (DMSO) was evaluated against Botrytis cinerea, that it is one of the phytopathogenic fungi which causes the greatest damage in agriculture. In in-vitro tests, the greatest inhibitory effect of DMSO on fungal grow was recorded at $\mathrm{pH} 6$. A significant growth inhibition was caused by $0.5 \%$ DMSO at $96 \mathrm{~h}$ post-inoculation. With higher DMSO concentrations, significant effects were recorded starting from $48 \mathrm{~h}$ post-inoculation. As the medium $\mathrm{pH}$ decreased, the inhibitory effect of DMSO also decreased. At pH 4 and 5 significant growth inhibition was caused by $1 \%$ DMSO starting from $72 \mathrm{~h}$ post-inoculation. At all tested $\mathrm{pH}$ values, a total growth inhibition was caused by $\geq 2 \%$ DMSO. On tomato leaves infected with $B$. cinerea, $2 \%$ DMSO significantly decreased the extent of damaged leaf area. The administration of DMSO at concentrations ranging from 0.5 to $2 \%$ through nebulization on leaves of young Solanum lycopersicum and Lactuca sativa plants did not change the chlorophyll fluorescence (Fv/Fm and $\Phi_{\text {PSII }}$ ) at any of the experimental times. Overall, the data obtained suggest that, at the concentrations tested, DMSO is toxic to $B$. cinerea, while it is well tolerated by lettuce and tomato plants.
\end{abstract}

ARTICLE HISTORY

Received 28 December 2019 Accepted 12 May 2020

\section{KEYWORDS}

Botrytis cinerea; dimethyl sulfoxide; antifungal activity; Solanum lycopersicum; Lactuca sativa; chlorophyll fluorescence

\section{Introduction}

The extensive use of conventional antifungals such as azoles and the consequent emergence of tolerant or resistant fungal strains (Ishii 2015; Price et al. 2015), have generated an increasing demand for new antifungal compounds (Simonetti et al. 2017). In this context, dimethyl sulfoxide (DMSO) could play a role in the fight against the pathogenic fungi, either directly by its intrinsic antifungal activity, or indirectly as a solvent able to enhance the activity of other antifungal compounds.

DMSO is an aprotic, dipolar, highly hygroscopic, watersoluble and stable compound. It is an extraordinary solvent, capable to dissolve a very wide spectrum of molecules, both polar and nonpolar. It is naturally present in trace amounts in fresh and marine waters, as well as in atmospheric precipitation (Manjunath and Shivaprakash 2013; Asher et al. 2017). DMSO is industrially produced quite inexpensively from lignin, that is a by-product of papermaking industry (Wörmeyer et al. 2011).

The favorable safety and toxicity profile of DMSO is supported by robust data accumulated over the last three decades (Marren 2011 and literature therein cited). This compound has a long history in pharmaceutics: the first trials of DMSO as pharmacologic agent were approved in 1963 by the Food and Drug Administration (FDA) (Santos et al. 2003). At present, the main medical use of DMSO is as penetrationenhancing solvent excipient, due to its ability to increase the permeability of skin barrier and rapidly cross biological membranes. Numerous studies demonstrated it to be effective in promoting the permeation of drugs, e.g., antibiotics, steroids and antiviral agents (Williams and Barry 2012). The penetrating ability of DMSO is believed to be due to its exchange and interchange for water in biological membranes (Manjunath and Shivaprakash 2013). In addition, DMSO is currently used to treat interstitial cystitis (Rawls et al. 2017). Several other potential therapeutic applications both on humans and animals are under study (Capriotti and Capriotti 2012; Manjunath and Shivaprakash 2013).

To date, investigations on the antifungal activity of DMSO are limited, and all of them are focused on human pathogenic fungi (Rodríguez-Tudela et al. 2001; Randhawa 2006, 2008; Randhawa and Aljabre 2007; León-García et al. 2017). To the best of our knowledge, no recent reports on the activity of DMSO against phytopathogenic fungi are available.

The ascomycete Botrytis cinerea Pers. ex Fr. (teleomorph Botryotinia fuckeliana (de Bary) Whetzel) is the causal agent of gray mold disease. It has been classified as the second most important plant pathogen, able to infect over 200 plant species (Dean et al. 2012). B cinerea can infect roots, stems, leaves, flowers and fruits, both by direct penetration and through wounds resulting from harvesting operations and handling before storage. Among its different hosts, the most economically relevant is grapevine (Vitis vinifera L.), followed

CONTACT A. Valletta alessio.valletta@uniroma1.it Department of Environmental Biology, Sapienza University of Rome, Piazzale Aldo Moro 5, 00185 Rome, Italy

*These authors equally contributed to the work

(C) 2020 Societá Botanica Italiana 
by tomato (Solanum lycopersicum L.), lettuce (Lactuca sativa L.) and others (Sowley et al. 2010; AbuQamar et al. 2017).

The aim of this study was to evaluate the antifungal activity of DMSO on B. cinerea. The activity of DMSO was tested in vitro at different concentrations (0.5-7\%) and medium $\mathrm{pH}$ (4-6), and on tomato leaves. In addition, the potential phytotoxicity of DMSO was investigated on tomato and lettuce plants through photosynthetic performance, evaluated in terms of chlorophyll fluorescence.

\section{Materials and methods}

\section{Material}

DMSO was purchased from Carlo Erba (Milan, Italy). Potato Dextrose Agar (PDA) and Potato Dextrose Broth (PDB) culture media were purchased from Formedium (Hunstanton, UK). The seeds used to obtain tomato (var. F.1 sugar) and lettuce (var. Lentisima a Montare 4) plants were purchased by Blumen (Milan, Italy). B. cinerea (Pers.) strain SF1 was obtained from Dr. S. Ferrari (University of Padua, Italy).

\section{In vitro antifungal assay of DMSO against B. cinerea}

The antifungal activity of DMSO was evaluated by mycelial radial growth inhibition technique, against $B$. cinerea grown on $3.9 \%$ PDB medium. Before sterilization by autoclaving at $1 \mathrm{~atm}$ and $121^{\circ} \mathrm{C}$ for 20 minutes, the $\mathrm{pH}$ of culture media was adjusted at 4,5 or 6 by adding $1 \mathrm{M} \mathrm{NaOH}$. DMSO was added to the culture media when they reached a temperature of $70-80^{\circ} \mathrm{C}$, before being poured into sterile Petri dishes ( $90 \mathrm{~mm}$ in diameter), each containing about $30 \mathrm{~mL}$ of medium. At the center of each plate, a $0.5 \mathrm{~cm}^{2}$ mycelial plug taken from the periphery of a 7-10 days old cultures of $B$. cinerea were inoculated. For each DMSO concentration, three replicates were used, as well as for the controls. The plates were incubated in a growth chamber under continuous darkness at $25 \pm 1{ }^{\circ} \mathrm{C}$. The mycelial radial growth measurements were carried out every $24 \mathrm{~h}$ with the free image analysis software Image J (https://imagej.nih.gov/ij/). The tolerance index (Rt:Rc) was calculated at all experimental times, as the ratio of the colony extension rates in the presence of DMSO (Rt) to the control extension rate (Rc) (Russo et al. 2019).

\section{B. cinerea inoculum preparation for in vivo bioassay}

Conidia were harvested from a two-week-old $B$. cinerea cultures grown under the conditions described above. An amount of five $\mathrm{mL}$ of $2.4 \%$ PDB sterile medium containing $0.05 \%(\mathrm{v} / \mathrm{v})$ Tween-80 (Sigma-Aldrich, Milan) was added to each dish. To facilitate conidia detachment, the plates were placed on an orbital shaker at $50 \mathrm{rpm}$ for $10-15$ minutes. To remove mycelia fragments, the conidia suspension was filtered through three layers of cheesecloth and then adjusted to a concentration of $1.0 \times 10^{5}$ conidia/mL with PDB liquid medium prior to use (Gabler and Smilanick 2001).

\section{Antifungal assay of DMSO against B. cinerea on tomato leaves}

One-month-old tomato plants were cultivated in a growth chamber at $25 \pm 1{ }^{\circ} \mathrm{C}, 60 \%$ relative humidity, under a photoperiod 16:8 light/dark. From each plant, the first fully developed leaf from the apex was taken. The cut was made at the base of the petiole. To prevent withering, the cut surfaces were coated with moist cotton wool, then the leaves were placed on 5 layers of absorbent paper soaked with demineralized water, inside glass Petri dishes $(15 \mathrm{~cm}$ in diameter). On the left side of leaves, 10 drops of conidia were placed (control), while on the right side an equal number of conidia suspension $\left(1 \times 10^{5}\right.$ conidia/ml) enriched with different concentrations of DMSO $(0,0.5,1$ or $2 \%)$ were placed. Each drop had a final volume of $5 \mu$ on both control and treated leaf side. Other controls were obtained by treating whole leaves with conidia suspensions with or without DMSO. The plates were left partially uncovered until the drops had dried, then they were kept in a growth chamber under the same conditions as above. Conidia germination, mycelium growth and the extent of leaf damage were monitored after 24,48 , and $72 \mathrm{~h}$ post-inoculation. The damaged leaf areas were measured using the image analysis software described above.

\section{Cell viability test trypan blue}

Trypan blue exclusion test was used to evaluate the viability of tomato mesophyll cells as described by Magrini et al. (2019).

\section{Chlorophyll fluorescence measurements on DMSO- treated plants}

Chlorophyll fluorescence measurements were carried out on 35-day-old tomato and lettuce plants grown in a growth chamber at $25 \pm 1{ }^{\circ} \mathrm{C}, 60 \%$ relative humidity, and photoperiod 16:8 light/dark. Plants were subjected to three different DMSO concentrations: $0 \%$ (control), $0.5 \%$ (C0.5), 1\% (C1) and $2 \%$ (C2). Each plant was treated with $3 \mathrm{~mL}$ of DMSO at different concentrations through nebulization, so as to form a uniform liquid film on the leaves. Control plants were treated with an equal volume of deionized water. Chlorophyll fluorescence measurements were carried after 0, 24 and $96 \mathrm{~h}$ (T0, T1, T2, and T3, respectively) by a portable modulated fluorometer (OS5p, Opti-Sciences, USA) and included maximum photochemical efficiency of the PSII (Fv/Fm) and actual quantum yield of photosynthesis $\left(\Phi_{\mathrm{PSII}}\right)$ calculated according to Maxwell and Johnson (2000). Specifically, Fv/Fm was calculated as (Fm-F0)/Fm, where F0 was the initial fluorescence and $\mathrm{Fm}$ the maximum fluorescence. Fv/Fm was calculated on leaves dark-adapted leaves for $30 \mathrm{~min}$ by leaf clips and then subjected to a saturating light pulse. $\Phi_{\mathrm{PSI}}$ was calculated on light-adapted leaves as (Fm'-Fs)/Fm', where $\mathrm{Fm}^{\prime}$ was the maximum fluorescence due to light saturating pulse $(\sim 8000 \mu \mathrm{mol}$ $\left.\mathrm{m}^{-2} \mathrm{~s}^{-1}\right)$ and Fs was the fluorescence steady-state fluorescence illuminated leaves $\left(1600 \mu \mathrm{mol} \mathrm{m} \mathrm{m}^{-2} \mathrm{~s}^{-1}\right)$. 
Table 1. Botrytis cinerea mycelial growth at different post-inoculation times on PDA culture medium at $\mathrm{pH} 4$ containing different DMSO concentrations.

\begin{tabular}{|c|c|c|c|c|c|}
\hline \multirow[b]{2}{*}{ DMSO concentration (\%) } & \multicolumn{5}{|c|}{ Time (hours) } \\
\hline & 0 & 24 & 48 & 72 & 96 \\
\hline 0 (control) & $0.50 \pm 0.00^{a}$ & $0.50 \pm 0.00^{a}$ & $2.71 \pm 0.52^{c}$ & $13.99 \pm 1.63^{\mathrm{e}, \mathrm{f}}$ & $32.04 \pm 2.89^{\jmath}$ \\
\hline 0.5 & $0.50 \pm 0.00^{a}$ & $0.50 \pm 0.00^{\mathrm{a}}$ & $2.50 \pm 0.60^{c}$ & $14.12 \pm 0.74^{f}$ & $32.05 \pm 1.70^{J}$ \\
\hline 1 & $0.50 \pm 0.00^{\mathrm{a}}$ & $0.50 \pm 0.00^{\mathrm{a}}$ & $2.85 \pm 0.37^{c}$ & $12.35 \pm 0.25^{\mathrm{e}}$ & $27.14 \pm 0.73^{h}$ \\
\hline 2 & $0.50 \pm 0.00^{\mathrm{a}}$ & $0.50 \pm 0.00^{\mathrm{a}}$ & $1.35 \pm 0.03^{b}$ & $5.12 \pm 1.16^{\mathrm{d}}$ & $8.10 \pm 2.38^{g}$ \\
\hline 4 & $0.50 \pm 0.00^{\mathrm{a}}$ & $0.50 \pm 0.00^{\mathrm{a}}$ & $0.50 \pm 0.00^{a}$ & $0.50 \pm 0.00^{\mathrm{a}}$ & $0.50 \pm 0.00^{a}$ \\
\hline 5 & $0.50 \pm 0.00^{\mathrm{a}}$ & $0.50 \pm 0.00^{\mathrm{a}}$ & $0.50 \pm 0.00^{\mathrm{a}}$ & $0.50 \pm 0.00^{\mathrm{a}}$ & $0.50 \pm 0.00^{\mathrm{a}}$ \\
\hline 6 & $0.50 \pm 0.00^{\mathrm{a}}$ & $0.50 \pm 0.00^{\mathrm{a}}$ & $0.50 \pm 0.00^{\mathrm{a}}$ & $0.50 \pm 0.00^{\mathrm{a}}$ & $0.50 \pm 0.00^{\mathrm{a}}$ \\
\hline 7 & $0.50 \pm 0.00^{\mathrm{a}}$ & $0.50 \pm 0.00^{\mathrm{a}}$ & $0.50 \pm 0.00^{\mathrm{a}}$ & $0.50 \pm 0.00^{\mathrm{a}}$ & $0.50 \pm 0.00^{\mathrm{a}}$ \\
\hline
\end{tabular}

The areas are expressed as square centimeters. Each value corresponds to the average of 3 independent measurements \pm S.D. Different letters indicate significant differences between samples $(p \leq 0.05)$.

Table 2. Botrytis cinerea mycelial growth at different post-inoculation times on PDA culture medium at pH 5 containing different DMSO concentrations.

\begin{tabular}{|c|c|c|c|c|c|}
\hline \multirow[b]{2}{*}{ DMSO concentration (\%) } & \multicolumn{5}{|c|}{ Time (hours) } \\
\hline & 0 & 24 & 48 & 72 & 96 \\
\hline 0 (control) & $0.50 \pm 0.00^{a}$ & $0.50 \pm 0.00^{a}$ & $2.28 \pm 0.38^{c}$ & $11.61 \pm 1.34^{f}$ & $25.03 \pm 2.09^{J}$ \\
\hline 0.5 & $0.50 \pm 0.00^{\mathrm{a}}$ & $0.50 \pm 0.00^{a}$ & $2.09 \pm 0.20^{c}$ & $10.75 \pm 0.60^{f}$ & $23.19 \pm 0.46^{h, J}$ \\
\hline 1 & $0.50 \pm 0.00^{\mathrm{a}}$ & $0.50 \pm 0.00^{\mathrm{a}}$ & $1.80 \pm 0.15^{b, c}$ & $9.26 \pm 0.53^{\mathrm{e}}$ & $21.51 \pm 0.17^{h}$ \\
\hline 2 & $0.50 \pm 0.00^{\mathrm{a}}$ & $0.50 \pm 0.00^{\mathrm{a}}$ & $1.31 \pm 0.11^{\mathrm{b}}$ & $4.61 \pm 0.28^{d}$ & $8.54 \pm 0.30^{g}$ \\
\hline 4 & $0.50 \pm 0.00^{\mathrm{a}}$ & $0.50 \pm 0.00^{\mathrm{a}}$ & $0.50 \pm 0.00^{\mathrm{a}}$ & $0.50 \pm 0.00^{a}$ & $0.50 \pm 0.00^{\mathrm{a}}$ \\
\hline 5 & $0.50 \pm 0.00^{\mathrm{a}}$ & $0.50 \pm 0.00^{\mathrm{a}}$ & $0.50 \pm 0.00^{\mathrm{a}}$ & $0.50 \pm 0.00^{a}$ & $0.50 \pm 0.00^{\mathrm{a}}$ \\
\hline 6 & $0.50 \pm 0.00^{\mathrm{a}}$ & $0.50 \pm 0.00^{\mathrm{a}}$ & $0.50 \pm 0.00^{a}$ & $0.50 \pm 0.00^{\mathrm{a}}$ & $0.50 \pm 0.00^{\mathrm{a}}$ \\
\hline 7 & $0.50 \pm 0.00^{\mathrm{a}}$ & $0.50 \pm 0.00^{\mathrm{a}}$ & $0.50 \pm 0.00^{\mathrm{a}}$ & $0.50 \pm 0.00^{\mathrm{a}}$ & $0.50 \pm 0.00^{\mathrm{a}}$ \\
\hline
\end{tabular}

The areas are expressed as square centimeters. Each value corresponds to the average of 3 independent measurements \pm S.D. Different letters indicate significant differences between samples $(p \leq 0.05)$.

Table 3. Botrytis cinerea mycelial growth at different post-inoculation times on PDA culture medium at pH 6 containing different DMSO concentrations.

\begin{tabular}{|c|c|c|c|c|c|}
\hline \multirow[b]{2}{*}{ DMSO concentration (\%) } & \multicolumn{5}{|c|}{ Time (hours) } \\
\hline & 0 & 24 & 48 & 72 & 96 \\
\hline 0 (control) & $0.50 \pm 0.00^{a}$ & $0.50 \pm 0.00^{a}$ & $1.91 \pm 0.31^{c}$ & $9.17 \pm 0.84^{f}$ & $18.00 \pm 1.39^{k}$ \\
\hline 0.5 & $0.50 \pm 0.00^{a}$ & $0.50 \pm 0.00^{a}$ & $1.72 \pm 0.27^{c}$ & $8.39 \pm 0.47^{f}$ & $15.75 \pm 0.33^{J}$ \\
\hline 1 & $0.50 \pm 0.00^{\mathrm{a}}$ & $0.50 \pm 0.00^{\mathrm{a}}$ & $1.41 \pm 0.12^{\mathrm{b}, \mathrm{c}}$ & $6.76 \pm 0.40^{\mathrm{e}}$ & $13.35 \pm 0.28^{h}$ \\
\hline 2 & $0.50 \pm 0.00^{\mathrm{a}}$ & $0.50 \pm 0.00^{a}$ & $0.97 \pm 0.08^{b}$ & $3.03 \pm 0.16^{d}$ & $4.72 \pm 0.12^{g}$ \\
\hline 4 & $0.50 \pm 0.00^{\mathrm{a}}$ & $0.50 \pm 0.00^{\mathrm{a}}$ & $0.50 \pm 0.00^{\mathrm{a}}$ & $0.50 \pm 0.00^{\mathrm{a}}$ & $0.50 \pm 0.00^{\mathrm{a}}$ \\
\hline 5 & $0.50 \pm 0.00^{\mathrm{a}}$ & $0.50 \pm 0.00^{\mathrm{a}}$ & $0.50 \pm 0.00^{\mathrm{a}}$ & $0.50 \pm 0.00^{\mathrm{a}}$ & $0.50 \pm 0.00^{\mathrm{a}}$ \\
\hline 6 & $0.50 \pm 0.00^{\mathrm{a}}$ & $0.50 \pm 0.00^{\mathrm{a}}$ & $0.50 \pm 0.00^{\mathrm{a}}$ & $0.50 \pm 0.00^{\mathrm{a}}$ & $0.50 \pm 0.00^{\mathrm{a}}$ \\
\hline 7 & $0.50 \pm 0.00^{\mathrm{a}}$ & $0.50 \pm 0.00^{\mathrm{a}}$ & $0.50 \pm 0.00^{\mathrm{a}}$ & $0.50 \pm 0.00^{\mathrm{a}}$ & $0.50 \pm 0.00^{\mathrm{a}}$ \\
\hline
\end{tabular}

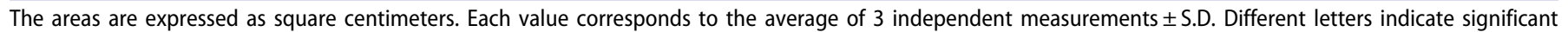
differences between samples $(p \leq 0.05)$.

\section{Statistical analysis}

The data were analyzed using a statistical Sigma Plot 12.0 software (Systat Software Inc., London, UK). The data of in vitro and in vivo experiments were analyzed by one-way ANOVA test. Differences were considered significant at $\mathrm{P}<0.05$.

\section{Results}

\section{In vitro inhibitory effect of DMSO on Botrytis cinerea growth}

To evaluate the effect of DMSO on B. cinerea in vitro growth, the fungus was inoculated in culture media containing different concentrations of DMSO (from 0.5 to $7 \%$ ). For each DMSO concentration, different $\mathrm{pH}$ values $(4,5$ and 6$)$ were tested. The mycelium radial growth was monitored every $24 \mathrm{~h}$. At all the pH values tested, the effect of different treatments began to be visible starting from $48 \mathrm{~h}$ post-inoculation (Tables 1-3).

Regardless of the presence of DMSO, the $\mathrm{pH}$ of the culture medium influenced the growth of $B$. cynerea. The maximum radial growth of control cultures was recorded at $\mathrm{pH} \quad 4\left(2.7 \mathrm{~cm}^{2}\right.$ at $48 \mathrm{~h}$ post-inoculation); a significantly $(\mathrm{p}<0.05)$ lower growth was observed at $\mathrm{pH} 5$ and 6 (2.3 and $1.9 \mathrm{~cm}^{2}$ at $48 \mathrm{~h}$ post-inoculation, respectively). The differences in growth rates at different $\mathrm{pH}$ levels increased with time (32.0, 25.0 and $18.0 \mathrm{~cm}^{2}$ at $96 \mathrm{~h}$ post-inoculation, at $\mathrm{pH} 4,5$ and 6 , respectively).

In Table 1, the data obtained on culture media at $\mathrm{pH} 4$ are reported. At $0.5 \%$ DMSO, no significant differences in radial growth compared to the control were observed. Significant differences between control and 1\% DMSO-treated samples were recorded at 72 and $96 \mathrm{~h}$ post-inoculation. In the samples treated with $2 \%$ DMSO, a significant growth inhibition was observed at all experimental times, except for $24 \mathrm{~h}$. At DMSO concentrations $>2 \%$, growth was completely inhibited and no increase in mycelium growth was recorded.

At $\mathrm{pH} 5,1 \%$ DMSO caused a significant growth inhibition at 72 and $96 \mathrm{~h}$ post-inoculation (Table 2). As observed at $\mathrm{pH}$ 4 , a significant growth inhibition was observed with $2 \%$ DMSO at 48,72 and $96 \mathrm{~h}$, and a total inhibition was caused by higher concentrations. 
At $\mathrm{pH}$ 6, a significant inhibitory effect was observed at $96 \mathrm{~h}$ post-inoculation, even with the lowest concentration of DMSO (0.5\%) (Table 3). With 1\% DMSO a significant inhibition was recorded at 72 and $96 \mathrm{~h}$ post-inoculation. At pH 6 the inhibitory effect of $2 \%$ DMSO was significant at 48,72 and $96 \mathrm{~h}$ post-inoculation. A $100 \%$ inhibition was caused by higher concentrations at all experimental times, as observed at lower $\mathrm{pH}$ values.

Table 4. Susceptibility of Botrytis cinerea to DMSO at different pHs, expressed as tolerance index (Rt:Rc).

\begin{tabular}{llllll}
\hline & & \multicolumn{4}{c}{ Time (hours) } \\
\cline { 3 - 6 } $\mathrm{pH}$ & DMSO concentration (\%) & $0-24$ & $24-48$ & $48-72$ & $72-96$ \\
\hline 4 & 0 (control) & 1.00 & 0.92 & 1.12 & 0.96 \\
& 0.5 & 1.00 & 1.14 & $0.74^{*}$ & 1.00 \\
& 1 & 1.00 & $0.47^{*}$ & 0.88 & $0.74^{*}$ \\
& 2 & 1.00 & $0.37^{*}$ & $0.26^{*}$ & $0.65^{*}$ \\
5 & 0 (control) & 1.00 & 0.91 & 1.01 & 1.01 \\
& 0.5 & 1.00 & 0.86 & 1.00 & 1.09 \\
& 1 & 1.00 & $0.73^{*}$ & $0.69^{*}$ & 0.81 \\
& 2 & 1.00 & $0.38^{*}$ & $0.28^{*}$ & $0.55^{*}$ \\
6 & 0 (control) & 1.00 & 0.90 & 1.01 & 0.96 \\
& 0.5 & 1.00 & 0.82 & 0.98 & 1.06 \\
& 1 & 1.00 & $0.69^{*}$ & $0.65^{*}$ & 0.80 \\
& 2 & 1.00 & $0.51^{*}$ & $0.32^{*}$ & $0.65^{*}$ \\
\hline
\end{tabular}

*Significant decrease in Rt:Rc compared to control.
The susceptibility of $B$. cynerea to DMSO was also evaluated through the tolerance index (Rt:Rc) (Table 4). The treatment with $0.5 \%$ DMSO caused a significant decrease in $\mathrm{Rt}: \mathrm{Rc}$ compared to the control, only at $\mathrm{pH} 4$ and after $48 \mathrm{~h}$ from the inoculation. One\% DMSO was effective at all experimental times, except for 48 and $72 \mathrm{~h}$ at $\mathrm{pH} 4$ and 5, respectively. The treatment with $2 \%$ DMSO caused a significant decrease in Rt:Rc at all experimental times and at all $\mathrm{pH}$ values.

\section{Effect of DMSO on tomato leaves infected with Botrytis cinerea}

To investigate the antifungal activity of DMSO in planta, drops of $B$. cinerea conidia suspensions were inoculated onto excised tomato plant leaves. On one half of each leaf, conidia suspended in culture medium without DMSO (control) were inoculated, while on the other half, conidia suspended in medium containing different DMSO concentrations were inoculated. The effects of DMSO on the extent of leaf damage were monitored at different post-inoculation times, up to $72 \mathrm{~h}$. It was not possible to carry out observations at longer experimental times, since the damage originated at the control leaf area had spread to most of the leaf blade.
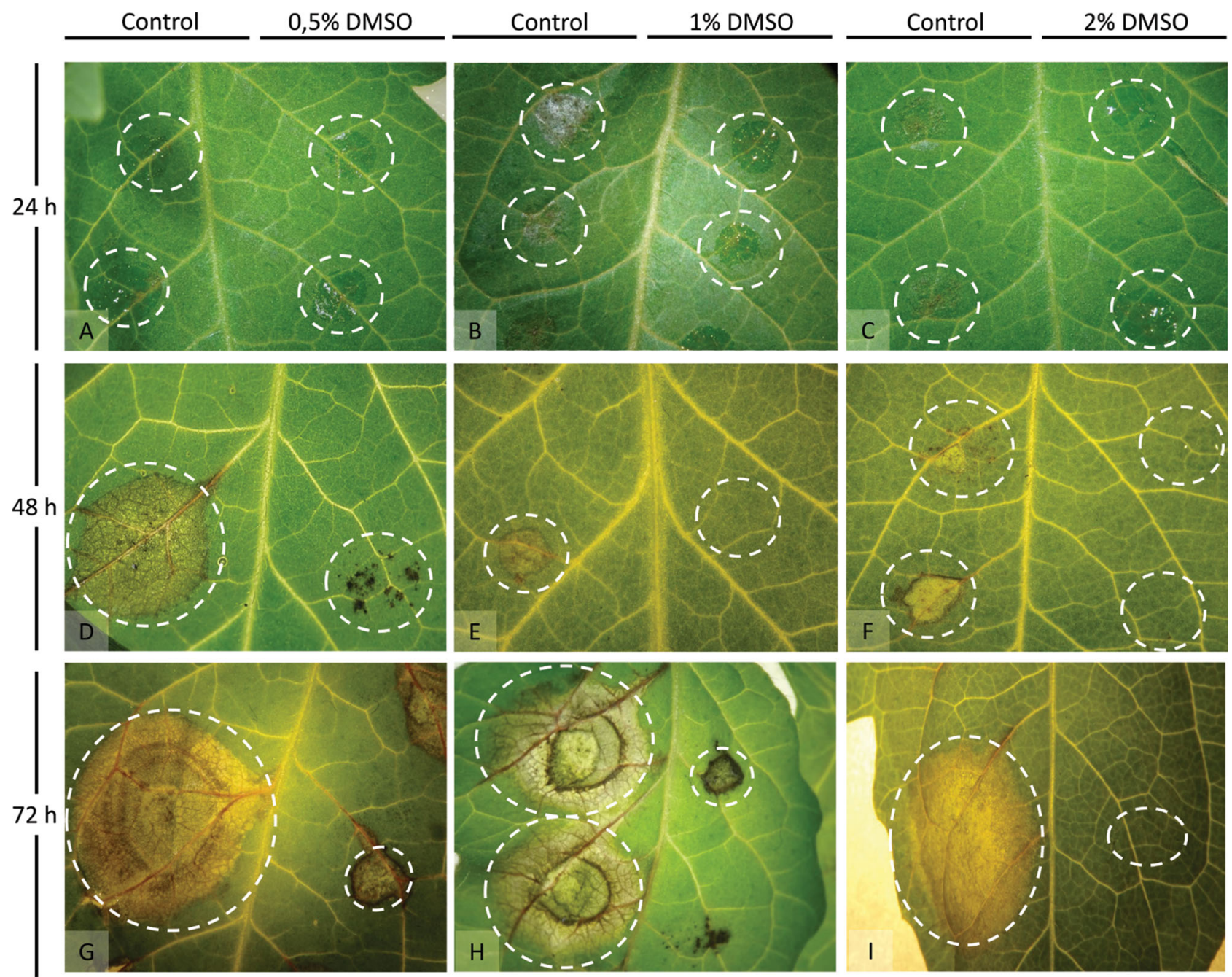

Figure 1. Tomato plant leaves infected with Botrytis cinerea conidia in absence (control) or in presence of different DMSO concentrations. 
At $24 \mathrm{~h}$ post-inoculation, differences between control and treated leaf areas were difficult to detect with the naked eye. However, observations carried out under a binocular microscope revealed the germination of several conidia and an initial mycelial growth in control leaf areas (Figure $1 \mathrm{~A}-\mathrm{C}$ ). In addition, the trypan blue test revealed several dead cells in control leaf areas (PCD). Conidia germination and mycelial growth in DMSO-treated areas were rarely observed.

After $48 \mathrm{~h}$ from the inoculation, the differences between control and treated leaf areas were clearly visible to the naked eye. Conidia germination and an initial mycelial growth occurred in most inoculation sites without DMSO, where large necrotic areas were often observed (Figure 1D-F).

At $48 \mathrm{~h}$ post-inoculation, the extent of leaf damage was lower as compared to the control with all tested DMSO concentrations; however, the differences were statistically significant only with $2 \%$ DMSO (Table 5). The mean extent of leaf damage was less than half (about $3.8 \mathrm{~cm}^{2}$ ) compared to that recorded in the control (about $7.8 \mathrm{~cm}^{2}$ ).

Table 5. Inhibitory effect of DMSO on Botrytis cinerea infection on Solanum lycopersicum leaves, expressed as damaged leaf area.

\begin{tabular}{llcc}
\hline & \multicolumn{3}{c}{ Time (hours) } \\
\cline { 2 - 4 } DMSO concentration (\%) & 0 & 48 & 72 \\
\hline $\mathbf{0}$ (Control) & 0 & $7.781 \pm 2.5^{\mathrm{a}}$ & $19.961 \pm 7.8^{\mathrm{c}}$ \\
$\mathbf{0 . 5} \%$ & 0 & $6.597 \pm 1.9^{\mathrm{a}}$ & $15.668 \pm 4.6^{\mathrm{c}}$ \\
$\mathbf{1} \%$ & 0 & $4.247 \pm 2.2^{\mathrm{a}}$ & $9.225 \mathrm{c} \pm 3.6^{\mathrm{c}}$ \\
$\mathbf{2} \%$ & 0 & $3.769 \pm 2.0^{\mathrm{b}}$ & $4.073 \mathrm{c} \pm 1.0^{\mathrm{d}}$ \\
\hline
\end{tabular}

The areas are expressed as square centimeters. Mean values were based on 10 replicates from three separate experiments \pm S.D. Different letters indicate significant differences between samples $(p \leq 0.05)$.

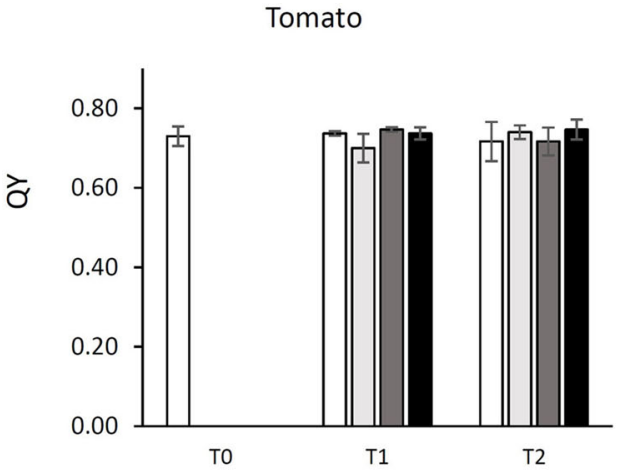

Tomato

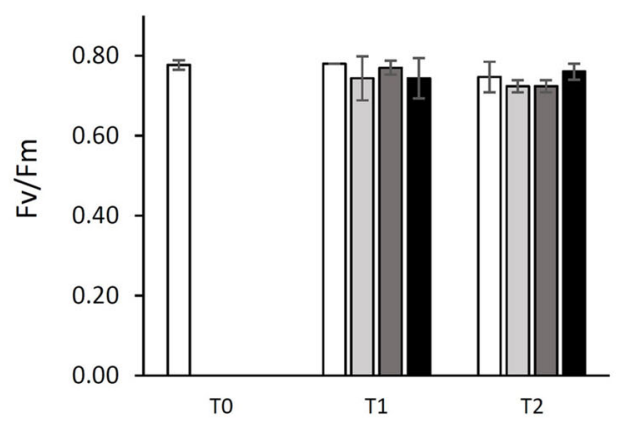

At $72 \mathrm{~h}$ post-inoculation the differences between control and DMSO-treated in the extent of leaf damage increased. However, even at this experimental time the differences were significant, only in presence of $2 \%$ DMSO, with which the average extent of leaf damage was about $1 / 5$ of the control (about 20.0 and $4.0 \mathrm{~cm}^{2}$, respectively).

\section{Chlorophyll fluorescence}

In tomato, the treatments with DMSO did not affect Fv/Fm and $\Phi_{P S I I}$ throughout the experiment (Figure 2). In lettuce, the tested DMSO concentrations did not induce significant differences in $\Phi_{\text {PSIII }}$. As for $\mathrm{Fv} / \mathrm{Fm}$, it did not significantly differ among $\mathrm{C} 05, \mathrm{C} 1$ and $\mathrm{C} 2$ at T1. Nevertheless, at T2 Fv/Fm was significantly lower at $\mathrm{C} 2$ than at $\mathrm{C} 05$ and $\mathrm{C} 1$ (Figure 2).

\section{Discussion}

Alternative strategies to reduce the use of synthetic pesticides for protection against plant diseases is becoming a necessity. Among these strategies, the most promising consist in the use of plant extracts rich in polyphenols or through stimulation and/or potentiation of the plant defense responses by the means of elicitors (Simonetti et al. 2020). This study is part of the investigating in the search alternative treatments for plant pest control.

Thanks to its ability to solubilize poorly water-soluble molecules, DMSO is used as a solvent in numerous antimicrobial tests. However, experimental evidence shows that DMSO,

Lettuce

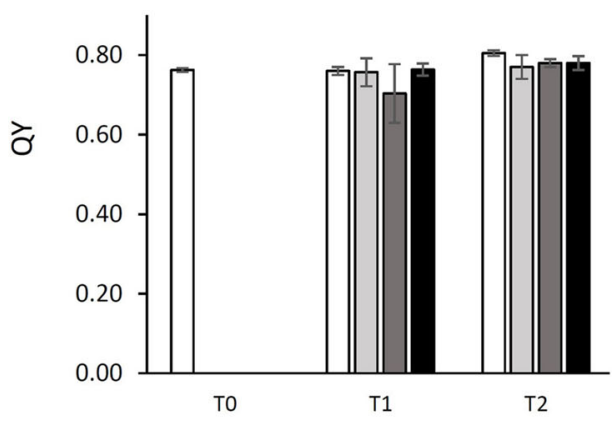

Lettuce

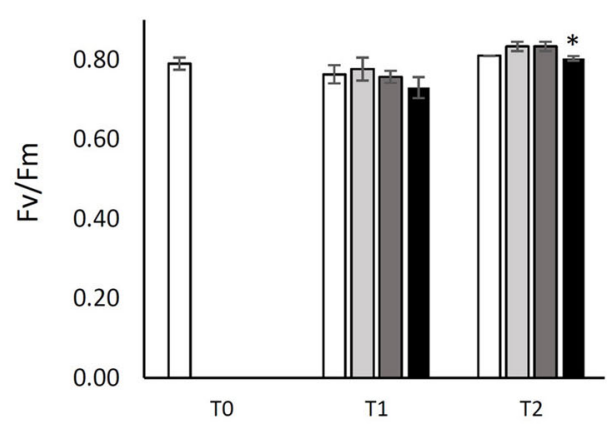

$\square$ Control $\square 0.5 \% \quad \square 1 \% \quad \square 2 \%$

Figure 2. $\Phi_{\mathrm{PSII}}$ and Fv/Fm values measured in tomato (Solanum lycopersicum) and lettuce (Lactuca sativa) plants treated with $0 \%$ (Control), $1 \%$ and $2 \%$ DMSO on days 0,24 and $48 \mathrm{~h}$ after treatment (T0, T1 and T2, respectively). The asterisk indicates a statistically significant difference $(P<0.05)$. 
even at relatively low doses, may exert an intrinsic antimicrobial activity and/or may potentiate the effects of the investigated antimicrobial compounds (Wadhwani et al. 2009). Already in 1968, Basch and Gadebusch (1968) demonstrated the in vitro antimicrobial activity of DMSO on different species of bacteria, fungi and protozoa. In 2009, Wadhwani and coworkers observed that DMSO, at concentrations ranging from 2 to $4 \%$, exerted an inhibitory activity on different bacterial strains, i.e., Shigella flexneri MTCC 1457, Staphylococcus epidermidis MTCC 435, Pseudomonas oleovorans MTCC 617, Vibrio cholerae MTCC 3906, and Salmonella paratyphi A. More recently, the antimicrobial activity of DMSO has been tested by Cevallos et al. (2017), who observed a growth inhibition of the protozoan Trypanosoma cruzi (the etiological agent of Chagas disease) in the presence of DMSO at concentrations $\geq 3 \%$.

The results obtained in this study show that DMSO exerts an antifungal activity even at relatively low concentrations. Similar results have been obtained in studies on human pathogenic fungi. In 2001, Rodríguez-Tudela et al. (2001) demonstrated that $2 \%$ DMSO significantly inhibit the growth of Candida sp. pl. In 2006, Randhawa showed an inhibitory effect of $<1 \%$ DMSO on dermatophytes; and in 2008 the same author established that DMSO inhibit the growth of germ tube of $T$. mentagrophytes arthrospores and C. albicans at concentrations ranging from 2.5 to $7.5 \%$. In 2007, Randhawa and Aljabre observed that the additive effect between DMSO and some antifungal drugs altered the results of antifungal activity tests. These literature data and the results obtained in this work, lead us to strongly advise against the use of DMSO as a solvent in antifungal activity tests, especially on fungal species that were found to be susceptible to DMSO. Even in other fungal species on which $\leq$ $1 \%$ DMSO does not significantly change the biomass growth rate, it may cause no visible changes that could alter the results of biological tests. It is therefore desirable that the standard protocols for antifungal activity tests that make use of DMSO as solvent be validated through non-targeted investigations (e.g., metabolomics, proteomics, and transcriptomics) to reveal the impact of this solvent on the biological system of interest.

In this study, we observed that the antifungal activity of DMSO on $B$. cynerea is $\mathrm{pH}$-dependent. At the lowest $\mathrm{pH}$ values tested, DMSO was active at a concentration of $1 \%$, while at higher $\mathrm{pH}$ values the antifungal activity was already detected at a concentration of $0.5 \%$. It should be emphasized that $B$. cinerea is an opportunistic necrotrophic fungus that can attack living, senescent, or decomposing tissues. The $\mathrm{pH}$ of plant tissues is highly variable, depending on the species, the organ, the degree of development and the state of decomposition. It is known, for example, that tomato fruit ripening is related to a decrease in acidity (Etienne et al. 2013). The pH of ripe tomatoes is about 4 (Anthon et al. 2011), which is also the optimum acidity for $B$. cinerea development, as confirmed in this study. The lower susceptibility of $B$. cinerea to DMSO at $\mathrm{pH} 4$, could be linked to a greater ability to recover after intoxication. From the applicative point of view, this result suggests that the simple treatment of plant foods with solutions that slightly reduce the surface
$\mathrm{pH}$ could increase the effectiveness of antifungal treatments in countering the development of $B$. cinerea.

The antifungal activity of DMSO was also tested on tomato leaves. Inhibition of fungal growth was observed with all concentrations of DMSO tested, however this was statistically significant only with $2 \%$ DMSO. In this regard, it should be stressed that the experiment was conducted in optimal conditions for the pathogen, which rarely occur in the field or in post-harvest. A high concentration of conidia was suspended in a relatively rich culture medium, the leaves were taken from young plants, and after pathogen inoculation the leaves were placed in an environment at mild temperature and high relative humidity. It is well known that the mild-humid climate is the most favorable for B. cinerea (Ciliberti et al. 2016). As far as atmosphere humidity is concerned, it should be considered that DMSO is highly hygroscopic. Under conditions of high atmospheric humidity, such as those in which the experiment was conducted, DMSO tends to hold water molecules from the surrounding environment. On the contrary, under field conditions water tends to evaporate with the consequent increase in DMSO concentration. Therefore, we expect that in the field, as well as in post-harvest, the antifungal activity is higher than that observed in this experiment.

Finally, we checked whether DMSO exerted phytotoxic effects at the concentrations tested. The phytotoxicity was evaluated by chlorophyll fluorescence measurements on young tomato and lettuce plants treated with DMSO at concentrations ranging from 0.5 to $2 \%$. This approach was chosen because alterations in chlorophyll fluorescence is one of the early stress responses used in several recent studies to assess phytotoxicity (Juneau and Popovic 1999; Kummerová et al. 2008; Gao et al. 2019). No significant variation of $\Phi_{\text {PSII }}$ and $\mathrm{Fv} / \mathrm{Fm}$ was observed, suggesting that DMSO is well tolerated by the species of interest.

The effect of DMSO on plant systems has been poorly investigated. In a recent study carried out on hydroponicallycultivated rice seedlings exposed to different DMSO concentrations for $72 \mathrm{~h}$, growth inhibition, protein content alteration, $\mathrm{H}_{2} \mathrm{O}_{2}$ accumulation in the root, and changes in antioxidant enzyme activity has been observed (Zhang et al. 2016). More recently, it was reported that DMSO enhanced the hypoosmotically induced increases in $\mathrm{Ca}^{2+}$ concentration in cytosolic and nucleic compartments of transgenic tobacco celllines (BY-2) expressing aequorin (Nguyen et al. 2019). These results are in contrast with those presented in this study. However, it should be considered that Zhang et al. (2016) added DMSO to the liquid medium of hydroponic cultures, where it comes into direct contact with the root, whose absorbing power is greater than that of the aerial organs. Also in the study by Nguyen et al. (2019), DMSO was added to the liquid medium, therefore, it is not surprising that the specific experimental system used led to a different plant response.

The low toxicity of DMSO at concentrations up to $10 \%$ has led to its widespread application in the medical field, mainly as a drug penetration enhancer (Williams and Barry 2012). However, in the last decade several authors have questioned the safety of DMSO on animals and humans, 
even at relatively low concentrations (Chen et al. 2011; Galvao et al. 2014).

In our opinion, the data obtained so far are not yet conclusive, so the impact of DMSO humans and their environment (animals and plants) will have to be thoroughly investigated to assess the potential of DMSO in agricultural practices.

\section{Conclusions}

The results presented in this study show that DMSO at relatively low concentrations exerts an antifungal activity on $B$. cinerea, one of the phytopathogenic fungi that causes the greatest damage in agriculture. To the best of our knowledge, the antifungal activity of DMSO on phytopathogenic fungi has never been investigated and this is the first report on this topic. Our results suggests that: i) DMSO should not be used as a solvent to test potential antifungal substances against $B$. cinerea strains, as it may modify their effects; ii) even in other species, the use of DMSO as solvent in antifungal tests should be evaluated, by investigating its effect not only on fungal growth, but also on effects that are not detectable macroscopically; iii) DMSO could be used in agriculture, both for its direct antifungal activity and for its ability to enhance the activity of other antifungal compounds. However, further studies are needed to verify the safety of this substance for the plant, the environment and humans.

\section{Acknowledgments}

The authors thank Professors Simone Ferrari and Daniela Bellincampi of Sapienza University of Rome for providing the fungal isolate used in this study.

\section{Data availability statement}

The data that support the findings of this study are available from the corresponding author upon reasonable request.

\section{Disclosure statement}

The authors declare that they have no conflict of interest.

\section{References}

AbuQamar S, Moustafa K, Tran LS. 2017. Mechanisms and strategies of plant defense against Botrytis cinerea. Crit Rev Biotechnol. 37(2): 262-274.

Anthon GE, LeStrange M, Barrett DM. 2011. Changes in pH, acids, sugars and other quality parameters during extended vine holding of ripe processing tomatoes. J Sci Food Agric. 91(7):1175-1181.

Asher EC, Dacey JWH, Stukel M, Long MC, Tortell PD. 2017. Processes driving seasonal variability in DMS, DMSP, and DMSO concentrations and turnover in coastal Antarctic waters. Limnol Oceanogr. 62(1): 104-124.

Basch H, Gadebusch HH. 1968. In vitro antimicrobial activity of dimethylsulfoxide. Appl Microbiol. 16(12):1953-1954.

Capriotti K, Capriotti JA. 2012. Dimethyl sulfoxide: history, chemistry, and clinical utility in dermatology. J Clin Aesthet Dermatol. 5(9):24-26.

Cevallos AM, Herrera J, López-Villaseñor I, Hernández R. 2017. Differential effects of two widely used solvents, DMSO and ethanol, on the growth and recovery of Trypanosoma cruzi Epimastigotes in culture. Korean J Parasitol. 55(1):81-84.

Chen TH, Wang YH, Wu YH. 2011. Developmental exposures to ethanol or dimethylsulfoxide at low concentrations alter locomotor activity in larval zebrafish: implications for behavioral toxicity bioassays. Aquat Toxicol. 102(3-4):162-166.

Ciliberti N, Fermaud M, Roudet J, Languasco L, Rossi V. 2016. Environmental effects on the production of Botrytis cinerea conidia on different media, grape bunch trash, and mature berries. Aust J Grape Wine Res. 22(2):262-270.

Dean R, Van Kan JA, Pretorius ZA, Hammond-Kosack KE, Di Pietro A, Spanu PD, Rudd JJ, Dickman M, Kahmann R, Ellis J, et al. 2012. The Top 10 fungal pathogens in molecular plant pathology. Mol Plant Pathol. 13(4):414-430.

Etienne A, Génard M, Lobit P, Mbeguié-A-Mbéguié D, Bugaud C. 2013. What controls fleshy fruit acidity? A review of malate and citrate accumulation in fruit cells. J Exp Bot. 64(6):1451-1469.

Gabler FM, Smilanick JL. 2001. Postharvest control of table grape gray mold on detached berries with carbonate and bicarbonate salts and disinfectants. Am J Enol Vitic. 52:12-20.

Galvao J, Davis B, Tilley M, Normando E, Duchen MR, Cordeiro MF. 2014. Unexpected low-dose toxicity of the universal solvent DMSO. FASEB J. 28(3):1317-1330.

Gao M, Liu Y, Song Z. 2019. Effects of polyethylene microplastic on the phytotoxicity of di-n-butyl phthalate in lettuce (Lactuca sativa L. var. ramosa Hort). Chemosphere. 237:124482.

Ishii H. 2015. Stability of resistance. In: Fungicide resistance in plant pathogens. Tokyo: Springer; p. 35-48.

Juneau P, Popovic R. 1999. Evidence for the rapid phytotoxicity and environmental stress evaluation using the PAM fluorometric method: importance and future application. Ecotoxicology. 8(6):449-455.

Kummerová M, Vánová L, Krulová J, Zezulka S. 2008. The use of physiological characteristics for comparison of organic compounds phytotoxicity. Chemosphere. 71(11):2050-2059.

León-García MC, Ríos-Castro E, López-Romero E, Cuéllar-Cruz M. 2017. Evaluation of cell wall damage by dimethyl sulfoxide in Candida species. Res Microbiol. 168(8):732-739.

Magrini S, Barreca D, Zucconi L. 2019. A rapid double-staining technique to improve seed viability testing in terrestrial orchids. Plant Biosyst. 153(6):877-882.

Manjunath P, Shivaprakash BV. 2013. Pharmacology and clinical use of dimethyl sulfoxide (DMSO): a review. IJMVR. 3:23-33.

Marren K. 2011. Dimethyl sulfoxide: an effective penetration enhancer for topical administration of NSAIDs. Phys Sportsmed. 39(3):75-82.

Maxwell K, Johnson GN. 2000. Chlorophyll fluorescence-a practical guide. J Exp Bot. 51(345):659-668.

Nguyen HT, Bouteau F, Mazars C, Kuse M, Kawano T. 2019. Enhanced elevations of hypo-osmotic shock-induced cytosolic and nucleic calcium concentrations in tobacco cells by pretreatment with dimethyl sulfoxide. Biosci Biotechnol Biochem. 83(2):318-321.

Price CL, Parker JE, Warrilow AG, Kelly DE, Kelly SL. 2015. Azole fungicides - understanding resistance mechanisms in agricultural fungal pathogens. Pest Manag Sci. 71(8):1054-1058.

Randhawa MA. 2006. The effect of dimethyl sulfoxide (DMSO) on the growth of dermatophytes. Nihon Ishinkin Gakkai Zasshi. 47(4): 313-318.

Randhawa MA, Aljabre SHM. 2007. Dimethyl sulfoxide (DMSO) has an additive effect and alters minimal inhibitory concentrations of antifungal drugs. J Rawalpindi Med Coll. 11(2):54-60.

Randhawa MA. 2008. Dimethyl sulfoxide (DMSO) inhibits the germination of Candida albicans and the Arthrospores of Trichophyton mentagrophytes. Nippon Ishinkin Gakkai Zasshi. 49:125-128.

Rawls WF, Cox L, Rovner ES. 2017. Dimethyl sulfoxide (DMSO) as intravesical therapy for interstitial cystitis/bladder pain syndrome: a review. Neurourol Urodyn. 36(7):1677-1684.

Rodríguez-Tudela JL, Cuenca-Estrella M, Díaz-Guerra TM, Mellado E. 2001. Standardization of antifungal susceptibility variables for a semiautomated methodology. J Clin Microbiol. 39(7):2513-2517.

Russo F, Ceci A, Maggi O, Siciliano A, Guida M, Papini MP, Cerník M, Persiani AM. 2019. Understanding fungal potential in the mitigation 
of contaminated areas in the Czech Republic: tolerance, biotransformation of hexachlorocyclohexane $(\mathrm{HCH})$ and oxidative stress analysis. Environ Sci Pollut Res Int. 26(24):24445-24461..

Santos NC, Figueira-Coelho J, Martins-Silva J, Saldanha C. 2003. Multidisciplinary utilization of dimethyl sulfoxide: pharmacological, cellular, and molecular aspects. Biochem Pharmacol. 65(7):1035-1041.

Simonetti G, Brasili E, D' Auria FD, Corpolongo S, Ferrari F, Pasqua G, Valletta A. 2017. Prenylated flavonoids and total extracts from Morus nigra L. root bark inhibit in vitro growth of plant pathogenic fungi. Plant Biosyst. 151(5):783-787.

Simonetti G, Pucci N, Brasili E, Valletta A, Sammarco I, Carnevale E, Pasqua G, Loreti S. 2020. In vitro antimicrobial activity of plant extracts against Pseudomonas syringae pv. actinidiae causal agent of bacterial canker in kiwifruit. Plant Biosyst. 154(1):100-106.
Sowley EN, Dewey FM, Shaw MW. 2010. Persistent, symptomless, systemic, and seed-borne infection of lettuce by Botrytis cinerea. Eur J Plant Pathol. 126(1):61-71.

Wadhwani T, Desai K, Patel D, Lawani D, Bahaley P, Joshi P, Kothari V. 2009. Effect of various solvents on bacterial growth in context of determining MIC of various antimicrobials. Internet J Microbiol. 7(1):1-13.

Williams AC, Barry BW. 2012. Penetration enhancers. Adv Drug Delivery Rev. 64:128-137.

Wörmeyer K, Ingram T, Saake B, Brunner G, Smirnova I. 2011. Comparison of different pretreatment methods for lignocellulosic materials. Part II: Influence of pretreatment on the properties of rye straw lignin. Bioresour Technol. 102(5):4157-4164.

Zhang XH, Yu XZ, Yue DM. 2016. Phytotoxicity of dimethyl sulfoxide (DMSO) to rice seedlings. Int J Environ Sci Technol. 13(2):607-614. 